\title{
Seboreik Dermatitte Güncel Yaklaşım
}

The Current Approach to Seborrheic Dermatitis

\author{
Seval DOĞRUK KAÇAR', Pınar ÖZUĞUZ'
}

'Afyon Kocatepe Üniversitesi Tıp Fakültesi Deri ve Zührevi Hastalıkları AD, Afyonkarahisar

\begin{abstract}
öz
Seboreik dermatit (SD) sebase bezlerin yoğun olduğu bölgelerde kronik tekrarlayan eritemli skuamlı plaklarla seyreden inflamatuvar bir deri hastalıktır. Halen pek çok bilinmeyenin olduğu patogenezde özellikle Malassezia türlerine bağlı gelişen lokal immün yanıt sorumlu tutulmaktadır. Bunun yanında Demodeks türleri, bazı ilaçlar, ultraviyole, hormonlar, çeşitli çevresel ve nütrisyonel faktörler de SD ile ilişkili bulunmuştur. Tedavide topikal antifungaller, topikal zayıf etkili kortikosteroidler ve kalsinörin inhibitörleri yanında dirençli hastalarda oral izotretinoin ya da itrakonazol tercih edilebilir. Bu derleme de SD etyopatogenez ve tedavideki bugün için bilinenler özetlenmiştir.
\end{abstract}

Anahtar Kelimeler: Etyopatogenez, seboreik dermatit, tedavi

\begin{abstract}
Seborrheic dermatitis (SD) is a chronic relapsing inflammatory skin disease characterized by erythematous and desquamated plaques in the areas where sebaseous glands are concentrated. Although there are still unknown mechanisms in the pathogenesis, especially a local immune reaction to Malassezia species is thought to be responsible. Besides Demodex species, drugs, ultraviolet, hormones, various environmental and nutritional factors are found to be related to SD. Topical antifungals, topical low potency corticosteroids and calcineurin inhibitors and in resistant cases oral isotretinoin and itraconazole are preferred in treatment. This review summarizes the currently known data on etiopathogenesis and treatment of SD.
\end{abstract}

Keywords: Etiopathogenesis, seborrheic dermatitis, treatment 


\section{GíRiş}

Seboreik dermatit (SD) toplumun \%3-5'ini etkileyen, erkeklerde daha sık olan kronik, yüzeyel, inflamatuvar bir hastalıktır. Kronik bir hastalık olmasına rağmen özellikle kış aylarında sıklığı ve şiddeti artar. Saçlı deri, kaş, göz kapağı, nazolabiyal kıvrımlar, dudak, kulak, sternal bölge, aksilla, meme altı, göbek, inguinal ve gluteal kıvrımları sıklıkla tutulur (1). Adolesan dönemde ve genç erişkinlerde insidansı yüksektir, ve yine 50 'li yaşlardan sonra hastalığın sıklığı artar (2). Tutulum bölgelerinin sebase bezlerden zengin olması sebebiyle artmış sebum üretimi patogenezde düşünülmüş ancak bu hasta grubunda yapılan çalışmalarda sebum sekresyon hızı ve sebum seviyeleri normal bulunmuştur (3). Bunun yanında avuç içi ve ayak tabanı gibi sebase bezlerin olmadığı bölgelerde SD görülmez. Bu nedenle SD sebase bölgelerin hastalığı olarak tanımlanmakla birlikte sebase bez hastalığı olduğu söylenemez.

\section{ETYOLOJI VE PATOGENEZ \\ Malassezia türleri ve SD}

Patogenezde en çok Malassezia furfur ya da onun maya formu Pityriosporium ovale'nin SD etyolojisindeki muhtemel rolü üzerinde durulmaktadır. İlk olarak 19. yüzyılın sonlarına doğru saçlı deride kepeklerde organizma gösterilmiştir (4). İlerleyen yıllarda Malassezia'nın normal floranın bir elemanı olarak rastlantısal bu hastalarda tespit edildiği aslında SD'nin psoriasis gibi epidermal hücre döngüsünde artışla sonuçlanan inflamatuar bir hastalığın sonucu olduğu hipotezi popülarite kazanmıştır (5). Ketakonazolün keşfiyle beraber bu antifungal ilacın verildiği hastalarda lezyonlarda iyileşme gösterilmiştir. Bunun üzerine malassezia teorisini yeniden öne çıkmıştır (6). Ayrıca bazı çalışmalarda P. ovale'ye karşı hücresel immün cevapta bozukluk gösterilmiştir (7). HIV pozitif ve AIDS'li hastalarda da hastalık insidansında artış olması da bu düşünceyi destekler. Buna göre hastaların bozuk immünitesine bağlı kommensal malassezia deride kolonize olarak patojen hale gelir. Tüm bu hipotezlere rağmen SD hastalarında spesifik bir T hücre bozukluğu gösterilememiştir. Ancak bir yayında Malassezia'ya karşı spesifik antikor düzeyleri artmış bulunmuştur (8). Organizmanın bir antijenine karşı gelişen bozuk immün yanıt hastalığı tetikliyor olabilir. Yüksek oranda immunojenik P.ovale'nin uzun süreli proinflamatuar etkilerine bağlı olarak kompleman aktivasyonu olur ve skualen gibi polyunsature deri yüzey lipidlerinden proinflamatuar reaktif okside metabolitler üretilir. Poliunsature yüzey lipidlerin içeriğindeki değişime bağlı olarak lokal immünolojik bozukluklar gelişir (9). Yapılan çalışmalarda 7 çeşit Malassezia türünden özellikle $M$ globosa ve $M$ restricta'nın sıklıkla ilişkili olduğu gösterilmiştir $(10,11)$. Günümüzde ileri genetik çalışmalarla alt tipleri belirlemek mümkün hale gelmiştir (12). Belki de yakın zamanda SD'e neden olan spesifik bir Malassezia alt tipi tespit edilebilir. Bunun yanında Lezyonlu deride Malassezia tarafından üretilen oleik asit ve malassezin gibi diğer inflamatuar moleküller bulunmuştur. Oleik asit skuam oluşumunu indüklerken, malassezin kontakt sensitizasyon yapan aryl hidrokarbon reseptörlerine bağlanarak immünostimulasyon yapar (13). Antifungal tedavi ile gerileyen hastalık ilacın kesilmesi ile sıklıkla tekrarlar. Bu da immünolojik bir bozukluk olduğu fikrini destekler. Ayrıca bazı çalışmalarda seboreik deri ve normal deri arasında Malassezia kolonizasyonu açısından fark gösterilememiş ve antifungal ilaçların antiinflammatuar mekanizmalarla etkili olduğu belirtilmiştir (2).

\section{Demodeks türleri ve SD}

Demodeks kıl follikülü ve sebase bezlerle yakın ilişkili saprofitik ektoparazittir. İnsanda 2 tipi mevcuttur: D. follicularum ve D. brevis. Sağlıklı deride demodeks yoğunluğu $<5 / \mathrm{cm} 2$ 'dir. Bir çalışmada demodeks ve yüzün SD benzeri lezyonları arasında bir ilişki gösterilmiştir (14). Ayrıca SD'li hastaların hem lezyonlu hem normal derilerinde normal popülasyona göre demodeks yoğunluğu artmış bulunmuştur (15). Bu da demodeksin hastalık etyolojisinde bir rolü olabileceğini düşündürür.

\section{İlaçlar ve SD}

Pekçok ilaçla SD benzeri lezyonlar geliştiği bildirilmiştir. Auranofin, aurotioglukoz, buspiron, klorpromazin, simetidin, etiyonamid, altın, griseofulvin, haloperidol, interferon-a, lityum, methoksalen, methildopa, fenotiazinler, psoralenler, stanozolol, tiyotiksen ve trioksalen tam olarak bilinmeyen bir mekanizma ile bu duruma yol açar (1). 


\section{Ultraviyole ve SD}

UV ışığının SD'i iyileştirdiği bildirilmiştir (16). Hatta bu hastalığın depresif bozukluklarda sık görülmesi hastaların güneşten uzak iç ortamda saha sık vakit geçirmesiyle ilişkilendirilmiştir (17). Ancak psoriasis için PUVA (Psoralen ile UVA) tedavisi alan hastalarda yüzde SD gelişimi de bildirilmiştir (18). Düşük sıcaklık ve nemin hastalığı arttırıcı etkileri de bilinmektedir. Merkezi ısınma yöntemlerinin kullanılması da durumu kötüleştirir.

\section{Hormonal faktörler ve SD}

SD puberte öncesi görülmezken sebase bezlerin en aktif oldukları dönemde hastalık insidansı en yüksektir. Hastalığın puberte ile başlaması yanında erkeklerde daha sık görülmesi androjenlerin pilosebase üniteye olan etkisini de düşündürmektedir. Ancak androgenetik alopesili hastalarda alopesik bölgelerde SD görülmez (19) Ayrıca hormonal bir ilişki olsa bayanlarda görülen SD'te, premenstrual dönem aknedekine benzer şekilde bir alevlenme beklenirdi. Yenidoğanda dolaşan maternal androjenlere bağIı olarak aktif sebase bezlerden sebum üretimi artmıştır (20). İnfantil SD'in doğumdan sonraki 3.-4. haftalarda azalma eğiliminde olması bunu destekler.

\section{Diğer faktörler ve SD}

Muhtemel çevresel, nütrisyonel faktörlerin ve yaşam tarzının etkilerini araştıran çeşitli yayınlar mevcuttur. Biotin, esansiyel yağ asitleri ve piridoksinin potansiyel etkileri araştırılmıştır. Özellikle infantil SD'te eksiklikleri saptanmıştır. Bakır ve magnezyum SD'li hastalarda yüksek bulunmuştur. Çinko eksikliğinde SD benzeri lezyonlar görülür. Aslında SD kötü hijyen koşullarıyla direkt ilişkili olmasa da özellikle depresyon ve alkolizmde kötü beslenme ve düşük hijyen koşulları hastalığı alevlendirir $(2,21)$.

Parkinson hastalarında sebore ve SD sıklığı artmıştır (22). L-Dopa tedavisi artmış sebum sekresyonunu baskılarken, normal sebum düzeylerine etki etmez (23). Seborenin predispozan bir faktör olduğu kabul edilebilir ancak primer etyolojik faktör değildir. Ayrıca sebum ekskresyon hızı ve hastalık aktivitesi arasında ilişki gösterilememiştir (24). Bu hastalarda artmış sebum üretimi Malassezia üremesini etkiler. Parkinson hastalarında artmış sebum üretiminin nörotro- pik olmaktan çok MSH üzerinden endokrin mekanizmalarla oluştuğu düşünülmektedir (25). Farklı açıdan bakan bir çalışmada aslında SD'inde ileri yaş grubunda bildirilenden sık olduğu ve bu iki hastalığın yaşa bağlı koinsidental birlikteliği olabileceğine dikkat çekmiştir (26).

Bugüne kadar SD patogenezinde çeşitli mekanizmalar düşünülmüş ancak henüz mekanizmalar tam açıklığa kavuşturulamamıştır. Varılan en son noktada hastalığın Malassezia türlerine bağlı gelişen lokal inflamatuar bir yanıt sonucu olduğu düşünülmektedir. Organizmanın ürettiği potansiyel irritan ve metabolitler hastalığı başlatabilir.

\section{KLINIK}

Aynı hastada farklı zamanlarda farklı klinik seyirler izlenebilir. Eritemli kuru skuamlı lezyonlar yanında daha şiddetli yağlı yapsşık skuamlı plaklar görülebilir. Lezyonlar genellikle simetriktir. SD saçlı deride sıklıkla görülürken kılların döküldüğü bölgelerde hiç lezyon görülmez. Tanı tipik klinik görünüm ve dağılım ile kolaylıkla konulur $(1,2)$.

Saçlı deride hastalık prevelansı bazı çalışmalarda \%50 bulunmuştur (27). Bu yükseklik hızlı şehirleşmeye bağlanabilir. Bu da çevresel faktörlerin hastalık patogenezinde etkili olduğunu gösterir.

HIV pozitif ve AIDS'li hastalarda SD sıklığı \%3483 gibi bildirilmiştir (2). Bu oran normal popülasyondaki, görülme sıklığı düşünüldüğünde en az 30 kat fazladır. Hastalığın sıklığı ve şiddeti ile HIV infeksiyonu evresi ve düşük CD4+ yardımcı T hücre sayıları arasında direkt ilişki vardır (28). Aslında bu hasta grubunda izlenen lezyonların daha psoriaziform, hiperkeratotik ve yaygın olması, farklı histopatoloji göstermesi hastalığın immünolojik bozukluklara bağlı gelişen SD benzeri, ayrı bir antite olabileceğini düşündürmüştür (29). Bunun yanında immünsupresyon arttıkça malassezia sayısındaki artışın bu şiddetli seyirden sorumlu olabilir. Bu hasta grubunun antifungal tedavilere yanıtı iyi değildir (30).

SD, Parkinson hastalığı ve HIV infeksiyonları ile daha sık birlikte bildirilmesinin yanında kalp hastalıkları, kronik renal yetmezlik, kronik pankreatit, hepatit $C$ virüs infeksiyonları ve çeşitli 
kanserlerle birlikteliği de bildirilmiştir. Ayrıca Down Sendromu, Hailey-hailey hastalığı ve kardiofasiyekutanöz sendromlarla da ilişkili bildirilmiştir (2).

\section{TEDAVi}

SD tedavisinde temel amaç, lezyonları ve fungal kolonizasyonu baskılamak ve sekonder enfeksiyonlara karşı önlem almaktır. Hastalığın yapısal olduğu, tekrarlayabileceği hastaya anlatılmalıdır. Hafif olgularda saçlı deride antiseboreik şampuanlar (Sedolin ${ }^{\circledR}$, Ceradolin $^{\oplus}$, Pirdolin ${ }^{\circledR}$ ) ve $\mathrm{pH}$ 'sı ayarlı sabunlar yeterli olabilir. Kalın kepekleri yumuşatmak için asit salisilikli yağlar kullanılabilir. Topikal tedaviler arasında katran, sülfür, salisilik içeren şampuanlar $\left(\operatorname{Kadolin}^{\circledR}\right)$, topikal kortikosteroidler (Momecon ${ }^{\circledR}, \mathrm{M}$-furo ${ }^{\circledR}$, Betnovate $^{\circledR}$, Dermovate ${ }^{\circledR}$, Hexacorton ${ }^{\circledast}$, UltraIan Crinale ${ }^{\circledR}$, Advantan $\mathrm{S}^{\circledR}$ ), takrolimus (Proto$\left.\mathrm{pic}^{\circledast}\right)$, pimekrolimus $\left(\right.$ Elidel $\left.^{\circledR}\right)$ ve $\% 2^{\prime}$ lik ketokonazol şampuan (Ketoral ${ }^{\circledR}$, Konazol $^{\circledR}$ ) şampuan ve kremler etkilidir. Saçlı deri ve göğüs ön yüzündeki lezyon alanları kıllı oldukları için kortikosteroidlerin losyon formu seçilir. Özellikle yüz lezyonlarında ve çocuklarda yan etkileri nedeniyle topikal kortikosteroidler kullanımına dikkat edilmelidir. Alevlenme dönemlerinde kısa süreli olarak zayıf etkili kortikosteroidler kullanılabilir. SD skuamlarından pitriyosporum ovale izole edildiğinden topikal olarak antifungal krem ve şampuanlar, özellikle de imidazol içerenler ile sonuçlar yüz güldürücü olmaktadır (31-33). Standart tedaviler arasında kortikosteroidler ve antimikotikler olmasına rağmen özellikle pimekrolimus, nonsteroidal topikal bir ilaç olduğu için, SD'de mükemmel bir alternatif tedavi seçeneği olarak kabul edilebilir $(33,34)$.

SD'li olgularda, \% 0.01 'lik takrolimus pomad tedavisi, \%1 lik hidrokortizon pomada göre daha etkin bir alternatif tedavidir (35).

İzotretinoinin, potent sebostatik etkisinden dolayı topikal tedavilere dirençli SD'li olgularda ya da lezyonlar yaygın olduğunda düşük doz (10mg/gün) kullanılabileceği gibi, kısa süreli sistemik kortikosteroidlerin kullanımı da önerilebilir (36-37). Ayrıca şiddetli SD'li olgulara itrakonazol 1 hafta $100 \mathrm{mg}$, günde 2 defa, takip eden 2 ayda da ayın ilk 2 günü 200 mg/gün verilebilir (38).
Sonuç olarak SD tekrarlayıcı, ataklarla seyreden, şiddeti kişiden kişiye değişkenlik gösteren, bazen sistemik hastalıklara eşlik ederken bazen ilaçlarla tetiklenebilen, tedavide farklı etki mekanizmaları nedeniyle çok çeşitli topikal ve sistemik alternatiflere sahip olan benign kronik bir hastalıktır. Nedeni henüz kesin olarak açıklanamamış olmasından dolayı, isminden farklı bakış açılarıyla değerlendirilmeye ve bu alanda çalışmalar planlamaya muhtaç bir alandır. Sosyal stigmaya da neden olabilen bu hastalar için, yakın geleceğin çözümlerle dolu olacağını umut ediyoruz.

\section{KAYNAKLAR}

1. Selden ST. Seborrheic dermatitis. http://www.emedicine. com/dermatology Last updated: 25.02.2013. Last accessed: 07.10.2013.

2. Gupta AK, Bluhm R. Seborrheic dermatitis. J Eur Acad Dermatol Venereol 2004;18(1):13-26.

3. Burton JL, Pye RJ. Seborrhoea is not a feature of seborrhoeic dermatitis. Br Med J 1983;286(6372):1169-70.

4. Malassez L. Note sur le champignon du pityriasis simple. Arch Physiol 1874;1: 451-9.

5. Ackerman AB, Kligman AM. Some observations on dandruff. J Soc Cosmet Chem 1969;21:81-5.

6. Shuster S. The aetiology of dandruff and the mode of action of therapeutic agents. Br J Dermatol 1984;111(2):235-42.

7. Bergbrant IM, Johansson S, Robbins D, et al. An immunological study in patients with seborrhoeic dermatitis. Clin Exp Dermatol 1991;16(5):331-8.

8. Midgley G, Hay RJ. Serological responses to Pityrosporum (Malassezia) in seborrhoeic dermatitis demonstrated by ELISA and Western blotting. Bull Soc Fr Med Mycol 1988;17:267-78.

9. DeAngelis YM, Gemmer CM, Kaczvinsky JR, et al. Three etiologic facets of dandruff and seborrheic dermatitis: Malassezia fungi, sebaceous lipids, and individual sensitivity. J Investig Dermatol Symp Proc 2005;10(3):295-7.

10. Gupta AK, Kohli Y, Summerbell RC, et al. Quantitative culture of Malassezia species from different body sites of individuals with or without dermatoses. Med Mycol 2001;39(3):243 -51.

11. Nakabayashi A, Sei Y, Guillot J. Identification of Malassezia species isolated from patients with seborrhoeic dermatitis, atopic dermatitis, pityriasis versicolor and normal subjects. Med Mycol 2000;38(5):337-41. 
12. Dawson TL. Malassezia globosa and restricta: breakthrough understanding of the etiology and treatment of dandruff and seborrheic dermatitis through whole-genome analysis. J Investig Dermatol Symp Proc 2007;12(2):15-9.

13. Hay RJ. Malassezia, dandruff and seborrhoeic dermatitis: an overview. Br J Dermatol 2011;165(2):2-8.

14. Karincaoglu Y, Bayram N, Aycan O, Esrefoglu M. The clinical importance of Demodex folliculorum presenting with nonspecific facial signs and symptoms. J Dermatol 2004;31(8):618-26.

15. Karincaoglu Y, Tepe B, Kalayci B, Atambay M, Seyhan M. Is Demodex folliculorum an aetiological factor in seborrhoeic dermatitis? Clin Exp Dermatol 2009;34(8):e516-20.

16. Berg M. Epidemiological studies of the influence of sunlight on the skin. Photodermatology 1989;6(2):80-4.

17. Marietta G, Rongioletti Rebora A. Seborrheic dermatitis and daylight. Acta Derm Venereol 1991;71(6):538-9.

18. Yegner E. Seborrhoeic dermatitis of the face induced by PUVA treatment. Acta Derm Venereol 1983;63(4):335-9.

19. Manuel F, Ranganathan S. A new postulate on two stages of dandruff: A clinical perspective. Int J Trichol 2011;3(1):3-6.

20. Henderson CA, Taylor J, Cunliffe WJ. Sebum excretion rates in mothers and neonates. Br J Dermatol 2000;142(1):110-1.

21. İnalöz HS, Kırtak N. The pathogenesis and treatment of seborrheic dermatitis. T Klin J Med Sci 2002;22(2):239-44.

22. Binder RL, Jonelis FJ. Seborrheic dermatitis in neurolepticinduced Parkinsonism. Arch Dermatol 1983;119(6):473-5.

23. Burton JL, Cartilidge M, Shuster S. Effect of L-dopa on the seborrhea of parkinsonism. Br J Dermatol 1973;88(5):475-9.

24. Burton JL, Cartlidge M, Cartlidge NEF, Shuster S. Sebum excretion in parkinsonism. Br J Dermatol 1973;88(3):263-6.

25. Shuster S, Thody AJ, Goolamali SK, et al. Melanocyte stimulating hormone and Parkinsonism. Lancet 1973;1(7801):463-4.

26. Mastrolonardo M, Diaferio A, Logroscino G. Seborrheic dermatitis, increased sebum excretion, and Parkinson's disease: a survey of (im)possible links. Med Hypotheses 2003;60(6):90711.

27. Ranganathan S, Mukhopadhyay T. Dandruff: The most commercially exploited skin disease. Indian J Dermatol 2010;55(2):130-4.

28. Shectman R, Midgley G, Hay RJ. HIV disease and Malassezia yeasts: a quantitative study of patients presenting with seborrhoeic dermatitis. Br J Dermatol 1995;133(5):694-8.
29. Soeprono FF, Schinella RA, Cockerell CJ, et al. Seborrheiclike dermatitis of acquired immunodeficiency syndrome. A clinicopathologic study. J Am Acad Dermatol 1986;14(2):242-8.

30. Wikler JR, Nieboer C, Willemze R. Quantitive skin cultures of Pityrosporum yeasts in patients seropositive for the human immunodeficiency virus with and without seborrheic dermatitis. J Am Acad Dermatol 1992;27(1):37-9.

31. Habif TP. Clinical Dermatology. Edinburg: Mosby, 2004;20966.

32. Savaskan H. Seboreik Dermatit. Dermatoloji Tüzün $Y$, Kotogyan A, Aydemir EH ve ark (Editörler). İstanbul: Nobel Tıp Kitabevleri, 1994;330-2.

33. Rigopoulos D, loannides D, Kalogeromitros D, Gregoriou $\mathrm{S}$, Katsambas A. Pimecrolimus cream $1 \%$ vs. betamethasone 17 -valerate $1 \%$ cream in the treatment of seborrhoeic dermatitis. A randomized open-label clinical trial. $\mathrm{Br} J$ Dermatol 2004;151(5):1071-5.

34. Ang-Tiu CU, Meghrajani CF, Maano CC. Pimecrolimus $1 \%$ cream for the treatment of seborrheic dermatitis: a systematic review of randomized controlled trials. Expert Rev Clin Pharmacol 2012;5(1):91-7.

35. Wananukul S, Chatproedprai S, Charutragulchai W. Randomized, double-blind, split-side comparison study of moisturizer containing licochalcone vs. $1 \%$ hydrocortisone in the treatment of infantile seborrhoeic dermatitis. J Eur Acad Dermatol Venereol 2012;26(7):894-7.

36. Plewig G, Jansen T. Seborrheic Dermatitis Fitzpatrick's Dermatology in General Medicine'de. Freedberg IM, Eisen AZ, Wolff KK, et al (Editors). New York: McGraw- Hill, 2003;1198-204.

37. Clark RAF, Hopkins TT. The other eczemas. Dermatology'de. Moschella SL, Hurley HJ (Editors). Philadelphia: WB Sounders Company, 1992;465-504.

38. Das J, Majumdar M, Chakraborty U, Majumdar V, Mazumdar G, Nath J. Oral itraconazole for the treatment of severe seborrhoeic dermatitis. Indian J Dermatol 2011;56(5):515-6. 